\title{
Menopause, menstrual and reproductive history, and bone density in northern Italy
}

\author{
Fabio Parazzini, Ettore Bidoli, Silvia Franceschi, Domenico Schinella, Franco Tesio, \\ Carlo La Vecchia, Romano Zecchin
}

Istituto di Ricerche Farmacologiche "Mario Negri", via Eritrea, 62, 20157 Milano, Italy

F Parazzini

C La Vecchia

Clinica OstetricoGinecologica, Università di Milano, via Commenda 12, 20100 Milano,

Italy

F Parazzini

Servizio di

Epidemiologia, Centro

di Riferimento

Oncologico, via

Pedemontana Occ.

33081 Aviano (PN),

Italy

E Bidoli

$S$ Franceschi

Divisione di

Emodialisi e

Nefrologia,

Stabilimento

Ospedaliero di

Pordenone,

via Montereale,

33170 Pordenone,

Italy

D Schinella

F Tesio

Istituto di Statistica

Medica e Biometria,

Università di Milano,

via Venezian 1,

20133 Milan,

Italy

C La Vecchia

Servizio di Medicina Nucleare, Stabilimento Ospedaliero di

Pordenone,

via Montereale,

33170 Pordenone,

Italy

$\mathrm{R}$ Zecchin

Correspondence to:

Dr F Parazzini.

Accepted for publication April 1996

\begin{abstract}
Study objective - To analyse the relationship between menstrual and reproductive factors and the risk of low bone mineral density (BMD).

Design - This was a population based screening programme carried out between 1991 and 1993 among 1373 perimenopausal women in northern Italy by means of dual photon absorptiometry at the lumbar spine.
\end{abstract}

Main results - BMD was strongly related to the age at menopause. In comparison with women reporting menopause below 45 years of age, the odds ratios (OR) of being in the lowest compared with the highest BMD tertile were 0.7 (95\% confidence interval (CI) $0.3,1.5)$ and $0.3(95 \%$ CI $0.1,0.8)$, respectively, in those with menopause at age $45-49$ and above 50 years: the trend in risk was significant. Likewise, the risk of being in the lowest tertile increased with years since the menopause. Compared with women who reported they had undergone the menopause less than two years before interview, the OR of being in the lowest BMD tertile were 2.1 (95\% CI 1.1,4.3), 2.3 (95\% CI 1.1, 5.0), and $5.7(95 \%$ CI $2.5,12.9)$ respectively in women who reported menopause $2-5$, $6-9$, and $\geq 10$ years earlier. The protective effect on bone density of late age at menopause was observed in different strata of years since menopause. Likewise, the increasing risk of a low BMD with increasing years since the menopause was evident in strata of different age at menopause. No relationships were observed between BMD and the age at menarche, characteristics of menstrual cycles, and the duration of menses. Likewise, no association emerged between reproductive history, including parity and age at first pregnancy, and BMD.

Conclusions - In this Italian population the risk of being in the lowest BMD tertile decreased with increasing age at menopause and increased with years since menopause. No relationships emerged between BMD and other menstrual characteristics or reproductive factors.

( $\mathcal{F}$ Epidemiol Community Health 1996;50:519-523)

Oestrogen concentrations are a major determinant of bone density in women. ${ }^{12}$ However, the role of menstrual and reproductive factors on the risk of osteoporosis is still unclear. There are few data on the issue, and some of these are controversial, particularly with regard to the role of reproductive factors. ${ }^{3-6}$ For example, there are some suggestions that amenorrhea may be accompanied by a decrease in bone density in athletes, ${ }^{6}$ and it is well recognised that after menopause the risk of low bone density increases. With regard to reproductive factors, some retrospective studies have shown a positive association between body mass and parity, but prospective ones did not confirm these results. ${ }^{5}$

Part of these controversial findings may be related to methodological problems in the definition of osteoporosis/low bone density, since bone mineral density (BMD) in the general population is normally distributed with little evidence of a threshold level. ${ }^{7}$

More generally, there is a paucity of data based on direct measurement of BMD in large groups of women, most epidemiological data being based on hip fractures or other clinically measurable consequences of osteoporosis.

In this paper, we present results on the relationship between reproductive and menstrual factors and the risk of low BMD, using data from a population based screening programme carried out among nearly 1400 perimenopausal women in northern Italy.

\section{Methods}

\section{STUDY POPULATION}

Between January 1991 and March 1993, all women between age 40 and 55 who permanently resided in two areas of Pordenone province (the northern district of Pordenone and the municipality of Fontanafredda), north eastern Italy, were offered the opportunity to join, free of charge, a BMD screening programmes. The programme was aimed at healthy women (ie, those not affected by recent malignancy or other severe conditions requiring long term immobilisation). Of 1812 women who were contacted by means of a personal invitation letter, 1111 agreed to participate (participation rate $61 \%$ ). In 1992 , the invitation was extended to 409 women aged 56-64 from the same areas, $262(64 \%)$ of whom agreed to participate. The study sample thus included 1373 women aged 40-64 (median age $=50$ years).

At the same time as BMD measurement, each woman was interviewed by a registered nurse in order to obtain information on sociodemographic factors, current and past weight, height, general lifestyle habits, smoking, men- 
Table 1 Distribution of 1373 women according to tertiles* of bone mineral density (BMD) at the lumbar spine according to age, education, body mass index, smoking habits, and hormone replacement therapy. Pordenone Province, north east Italy, 1991-93

\begin{tabular}{|c|c|c|c|c|c|c|}
\hline & \multicolumn{6}{|c|}{$B M D$ tertiles } \\
\hline & \multicolumn{2}{|c|}{ Low $(n=458)$} & \multicolumn{2}{|c|}{ Intermediate $(n=454)$} & \multicolumn{2}{|c|}{$\operatorname{High}(n=461)$} \\
\hline & No & $\%$ & No & $\%$ & No & $\%$ \\
\hline \multicolumn{7}{|l|}{ Age (y): } \\
\hline $40-44$ & 79 & 17.2 & 93 & 20.5 & 105 & 22.8 \\
\hline $45-49$ & 128 & 27.9 & 134 & 29.5 & 132 & 28.6 \\
\hline $50-54$ & 131 & 28.6 & 115 & 25.3 & 139 & 30.3 \\
\hline $55-59$ & 63 & 13.8 & 77 & 17.0 & 60 & 13.0 \\
\hline \multicolumn{7}{|l|}{ Education (y): } \\
\hline$<6$ & 195 & 43.0 & 194 & 43.1 & 202 & 44.0 \\
\hline $6-8$ & 122 & 26.9 & 125 & 27.8 & 121 & 26.4 \\
\hline \multirow{2}{*}{\multicolumn{7}{|c|}{ Body mass index $\left(\mathrm{kg} \cdot \mathrm{m}^{1.5}\right)$ : }} \\
\hline & & & & & & \\
\hline$<28.0$ & 128 & 28.3 & 81 & 18.2 & 53 & 11.7 \\
\hline $28.0-30.2$ & 86 & 19.0 & 90 & 20.2 & 101 & 22.3 \\
\hline $30.3-32.5$ & 79 & 17.4 & 97 & 21.7 & 78 & 17.3 \\
\hline $32.6-35.9$ & 86 & 19.0 & 102 & 22.9 & 100 & 22.1 \\
\hline$\geq 36.0$ & 74 & 16.3 & 76 & 17.0 & 120 & 26.5 \\
\hline \multicolumn{7}{|l|}{ Smoking habits: } \\
\hline Ex-smokers & 59 & 12.9 & 56 & 12.3 & 59 & 12.9 \\
\hline \multicolumn{7}{|l|}{ Current smokers } \\
\hline$<15 \mathrm{cig} / \mathrm{d}$ & 55 & 12.0 & 60 & 13.2 & 53 & 11.5 \\
\hline$\geq 15 \mathrm{cig} / \mathrm{d}$ & 27 & 5.9 & 22 & 4.8 & 20 & 4.4 \\
\hline \multicolumn{7}{|l|}{ Hormone replacement therapy: } \\
\hline Never & 424 & 92.8 & 416 & 91.8 & 438 & 95.0 \\
\hline$<12 \mathrm{mth}$ & 16 & 3.5 & 25 & 5.5 & 9 & 2.0 \\
\hline$\geq 12 \mathrm{mth}$ & 17 & 3.7 & 12 & 2.6 & 14 & 3.0 \\
\hline
\end{tabular}

* Some columns do not add up to the total because of missing values.

strual and reproductive factors, and lifelong history of potentially relevant medical conditions.

\section{EXAMINATION}

BMD was measured by means of dual photon absorptiometry which was fitted with a gadolinium-153 $\left({ }^{153} \mathrm{Gd}\right)$ source. Antero-posterior measurements were performed in lumbar vertebrae L 2-4 and the mean value was expressed as $\mathrm{g} / \mathrm{cm}^{2}$. The coefficient of variation from repeated measures was $2 \%$. The ${ }^{153} \mathrm{Gd}$ source was replaced immediately before the beginning of this study and twice during the 26 month period of data collection (summer months excluded). Calibration was undertaken before each clinic session according to the manufacturer's recomendations; generally, eight women were measured during each session. Two technicians conducted all measurements. Data inspection showed no evidence of systematic variations in BMD measurements according to age of the ${ }^{153} \mathrm{Gd}$ source or the season.

Height and weight were measured with the participants wearing light clothing and without shoes. Waist circumference $(\mathrm{cm}$ ) (at the narrowest part of mid-section) and hip circumference $(\mathrm{cm})$ below the waist were measured by the interviewing nurse.

\section{DATA ANALYSIS}

Premenopausal women and postmenopausal ones (defined as those who reported that they had not had menstrual cycles for at least 12 months) were grouped, separately, according to approximate tertiles of BMD. The cut off points of BMD tertiles were 0.992 and 1.104 in premenopausal women and 0.846 and 0.960 in postmenopausal ones. The lowest BMD tertile was compared with the highest one according to the distribution of various char- acteristics. The odds ratios (OR) and corresponding $95 \%$ confidence intervals (CI) between extreme tertiles were computed using unconditional multiple logistic regression equations, ${ }^{9}$ which included terms for age, menopausal status, and body mass index (BMI) in quintiles. We also analysed the data, using BMD as a continuous otucome variable. Multivariate linear regression models were used to assess the relationship between $\mathrm{BMD}$ and the explanatory variables of interest, again as continuous variables. Included in the regression equations were terms for age at diagnosis, body mass index and, when appropriate, menopausal status. Body mass index was computed as weight $(\mathrm{kg}) /$ height $\left(\mathrm{m}^{1.5}\right),{ }^{15}$ which has been shown to be a weight for height index independent from height. "Smokers" were women who reported having smoked at least one cigarette a day for as long as a year, and "ex-smokers" those who had stopped smoking for at least a year.

\section{Results}

Table 1 shows the distribution of subjects in relation to $\mathrm{BMD}$ tertile and age, education, body mass index, smoking, and use of hormone replacement treatment. Women in the highest tertile of weight were less frequently in the lowest BMD tertile. Women in the highest quintile of weight ( $\geq 75 \mathrm{~kg}$ ) were at an approximately fivefold reduced risk of being in the lowest tertile compared with those in the lowest quintile of weight (OR for women $\geq 75 \mathrm{~kg}$ compared with those $<57 \mathrm{~kg}=0.2$; $95 \%$ CI $0.1,0.3)$. Current smokers of 15 cigarettes per day or more were slightly overrepresented in the lowest compared with the highest BMD tertile. Those who had ever used oestrogen replacement therapy were more frequently in the highest tertiles of BMD than women who had never used this therapy. The former had an OR of 1.3 (95\% CI 0.7,2.6) of being in the lowest compared with the highest BMD tertiles, but OR estimates were not related to the duration of use.

The relationship between selected menstrual characteristic and BMD is considered in table 2. No clear relationships emerged in either premenopausal and postmenopausal women between BMD and age at menarche, regularity of menstrual cycles, and duration of menstrual cycle and bleeding. Age at menopause was strongly related to BMD. Compared with women who reported menopause below 45 years of age, the OR of being in the lowest compared with the highest BMD tertile were 0.6 and 0.3 , respectively, in those with menopause at age $45-49$ and above 50 years: the trend in risk was significant. Likewise, the risk of being in the lowest tertile increased greatly with the years since menopause. Compared with women who reported that they had undergone menopause less than two years before the interview, the OR of being in the lowest BMD tertile were $2.1,2.3$, and 5.7 , respectively, in women who had gone through the menopause $2-5,6-9$, and $\geq 10$ years earlier.

We have further analysed the relation between BMD and age at menopause in strata of 
Table 2 Odds ratios (OR) for the lowest compared with the highest bone mineral density (BMD) tertile at the lumbar spine according to selected menstrual characteristics and menopausal status. Pordenone Province, north east Italy, 1991-93

\begin{tabular}{|c|c|c|c|c|}
\hline & $\begin{array}{l}\text { Low:high } \\
\text { BMD tertile* }\end{array}$ & $\begin{array}{l}\text { Premenopausal } \\
\text { women } \\
\text { OR }(95 \% \text { CI }) \dagger\end{array}$ & $\begin{array}{l}\text { Postmenopausal } \\
\text { women } \\
\text { OR }(95 \% \text { CI })\end{array}$ & $\begin{array}{l}\text { All } \\
\text { OR }(95 \% C I) \dagger\end{array}$ \\
\hline $\begin{array}{l}\text { Age at menarche }(y): \\
<12 \\
12-13 \\
\geq 14 \\
\chi^{2}{ }_{1} \text { trend } \\
\text { Lifelong menstrual pattern (d): }\end{array}$ & $\begin{array}{c}71: 82 \\
199: 220 \\
185: 159\end{array}$ & $\begin{array}{l}1 \\
1.0(0.6,1.6) \\
0.9(0.5,1.5) \\
0.3\end{array}$ & $\begin{array}{l}1 \\
1.0(0.6,1.9) \\
1.7(0.9,3.1) \\
4.3 \ddagger\end{array}$ & $\begin{array}{l}1 \\
1.0(0.7,1.5) \\
1.2(0.8,1.8) \\
1.1\end{array}$ \\
\hline $\begin{array}{l}<26 \\
26-30 \\
\geq 31 \\
\text { Totally irregular } \\
\text { Duration of menstrual bleeding (d): }\end{array}$ & $\begin{array}{c}88: 86 \\
309: 326 \\
35: 21 \\
22: 25\end{array}$ & $\begin{array}{l}1 \\
0.8(0.5,1.3) \\
1.7(0.7,3.8) \\
1.1(0.4,2.7)\end{array}$ & $\begin{array}{l}1 \\
1.2(0.7,2.0) \\
1.4(0.5,4.3) \\
0.9(0.3,2.5)\end{array}$ & $\begin{array}{l}1 \\
1.0(0.7,1.4) \\
1.6(0.8,3.1) \\
1.0(0.5,1.9)\end{array}$ \\
\hline $\begin{array}{l}<5 \\
5-6 \\
\geq 7 \\
\chi^{2}{ }_{1} \text { trend } \\
\text { Menopausal status: }\end{array}$ & $\begin{array}{l}140: 158 \\
204: 215 \\
109: 83\end{array}$ & $\begin{array}{l}1 \\
1.1(0.7,1.6) \\
1.4(0.8,2.5) \\
1.3\end{array}$ & $\begin{array}{l}1 \\
1.1(0.7,1.8) \\
1.2(0.7,2.1) \\
0.6\end{array}$ & $\begin{array}{l}1 \\
1.1(0.8,1.5) \\
1.3(0.9,1.9) \\
1.8\end{array}$ \\
\hline $\begin{array}{l}\text { Premenopausal } \\
\text { Postmenopausal }\end{array}$ & $\begin{array}{l}245: 245 \\
213: 216\end{array}$ & - & - & $\begin{array}{l}1 \\
0.8(0.6,1.1)\end{array}$ \\
\hline $\begin{array}{l}\text { Age at menopause }(\mathrm{y}): \\
<45 \\
45-49 \\
\geq 50 \\
\chi_{1}^{2}{ }_{1} \text { trend } \\
\text { Years since menopause: }\end{array}$ & $\begin{array}{l}49: 43 \\
73: 61 \\
88: 109\end{array}$ & - & $\begin{array}{l}1 \\
0.6(0.3,1.2) \\
0.3(0.2,0.6) \\
14.4 \S\end{array}$ & - \\
\hline $\begin{array}{l}<2 \\
2-5 \\
6-9 \\
\geq 10 \\
\chi_{1}^{2} \text { trend }\end{array}$ & $\begin{array}{l}17: 42 \\
67: 83 \\
50: 52 \\
75: 34\end{array}$ & - & $\begin{array}{l}1 \\
2.1(1.1,4.3) \\
2.3(1.1,5.0) \\
5.7(2.5,12.9) \\
17.9 \oint\end{array}$ & 二 \\
\hline
\end{tabular}

$1=$ reference category.

* Some strata do not add up to the total because of missing values.

† Odds ratios (OR) and $95 \%$ confidence intervals (CI) from unconditional multiple logistic regression equations including terms for age in quinquennia, body mass index in quintiles, and, when appropriate, menopausal status. $\ddagger=\mathrm{p}<0.05 ; \oint=\mathrm{p}<0.01$.

Table 3 Odds ratios for the lowest compared to the highest bone mineral density (BMD) tertile at the lumbar spine according to age at menopause in strata of years since menopause. Pordenone Province, north east Italy, 1991-93

\begin{tabular}{|c|c|c|c|c|c|c|c|}
\hline \multirow[t]{2}{*}{ Age at menopause* } & \multicolumn{3}{|c|}{$\begin{array}{l}\text { Years since menopause } \\
<4\end{array}$} & \multicolumn{3}{|l|}{$\geq 4$} & \multirow[t]{2}{*}{ All } \\
\hline & $\begin{array}{l}\text { BMD tertile } \\
\text { Low }\end{array}$ & High & OR $(95 \% C I) \dagger$ & $\begin{array}{l}\text { BMI } \\
\text { Low }\end{array}$ & High & OR $(95 \% C I) \dagger$ & \\
\hline $\begin{array}{l}<45 \\
45-49 \\
\geq 50 \\
\chi^{2}, \text { (trend) }\end{array}$ & $\begin{array}{r}7 \\
18 \\
28\end{array}$ & $\begin{array}{r}6 \\
28 \\
58\end{array}$ & $\begin{array}{l}1 \\
0.6(0.1,2.9) \\
0.6(0.1,3.9) \\
0.2\end{array}$ & $\begin{array}{l}42 \\
55 \\
59\end{array}$ & $\begin{array}{l}37 \\
32 \\
50\end{array}$ & $\begin{array}{l}1 \\
0.7(0.3,1.5) \\
0.3(0.1,0.8) \\
7.1 \ddagger\end{array}$ & $\begin{array}{l}1 \\
\mathbf{0 . 7}(0.4-1.4) \\
0.4(0.2-0.8) \\
7.8 \ddagger\end{array}$ \\
\hline
\end{tabular}

* Some strata do not add up to the total because of missing values.

t Odds ratios (OR) and $95 \%$ confidence interval (CI) from unconditional multiple logistic regression equations including terms for age in quinquennia and body mass index in quintiles and years since menopause for the estimates for the whole series. $1=$ reference category.

$\ddagger \mathrm{p}<0.01$.

Table 4 Odds ratios for the lowest compared with the highest bone mineral density (BMD) tertile at the lumbar spine according to years since menopause in strata of age at menopause. Pordenone Province, north east Italy 1991-93

\begin{tabular}{|c|c|c|c|c|c|c|c|}
\hline \multirow[t]{3}{*}{ Years since menopause* } & \multicolumn{6}{|c|}{ Age at menopause $(y)$} & \multirow{3}{*}{ All } \\
\hline & \multicolumn{3}{|l|}{$<50$} & \multicolumn{3}{|l|}{$\geq 50$} & \\
\hline & $\begin{array}{l}\text { BMD tertile } \\
\text { Low }\end{array}$ & High & OR $(95 \% C I) \dagger$ & $\begin{array}{l}\text { BMD } \\
\text { Low }\end{array}$ & High & OR $(95 \% C I) \dagger$ & \\
\hline $\begin{array}{l}<2 \\
2-3 \\
4-5 \\
6-7 \\
8-9 \\
\geq 10 \\
\chi^{2}{ }_{1} \text { (trend) }\end{array}$ & $\begin{array}{r}6 \\
19 \\
17 \\
13 \\
12 \\
55\end{array}$ & $\begin{array}{l}14 \\
20 \\
17 \\
12 \\
12 \\
28\end{array}$ & $\begin{array}{l}1 \\
2.4(0.7,8.0) \\
2.3(0.7,8.1) \\
2.5(0.7,9.9) \\
2.5(0.6,9.9) \\
3.8(1.1,13.4) \\
3.0\end{array}$ & $\begin{array}{l}11 \\
17 \\
14 \\
11 \\
14 \\
20\end{array}$ & $\begin{array}{r}28 \\
30 \\
16 \\
17 \\
11 \\
6\end{array}$ & $\begin{array}{l}1 \\
1.5(0.5,4.4) \\
1.8(0.5,6.5) \\
1.3(0.3,5.5) \\
2.4(0.5,11.1) \\
7.7(1.3,46.9) \\
3.2\end{array}$ & $\begin{array}{l}1 \\
1.9(0.9,4.0) \\
2.0(0.9,4.7) \\
1.7(0.7,4.3) \\
2.5(0.8,5.4) \\
4.1(1.6,10.7) \\
6.1 \neq\end{array}$ \\
\hline
\end{tabular}

* Some strata do not add up to the total because of missing values.

t Odds ratios (OR) and $95 \%$ confidence interval (CI) from unconditional multiple logistic regression equations including terms for age in quinquennia and body mass index in quintiles and age at menopause for the estimates for the whole series. $1=$ reference category $\ddagger \mathrm{p}<0.05$.

years since menopause and vice versa. The protective effect of late age at menopause on $\mathrm{BMD}$ was similar in the different strata of years since menopause: the OR of being in the lowest BMD tertile compared with the highest one were 0.6 and 0.3 respectively for age at menopause $\geq 50$ years in comparison with $<45$ in women reporting menopause $<4$ years and $\geq 4$ years before interview (table 3). Likewise, the increasing risk of low BMD with increasing years since menopause was similar in strata of different age at menopause. BMD in relation to age since menopause showed a rapid decline in two to three years, but the trend with in- 
Table 5 Odds ratios for the lowest compared with the highest bone mineral density (BMD) tertile at the lumbar spine according to reproductive factors. Pordenone Province, north east Italy, 1991-93

\begin{tabular}{|c|c|c|c|c|}
\hline & $\begin{array}{l}\text { BMD tertile* } \\
\text { Low:high }\end{array}$ & $\begin{array}{l}\text { Premenopausal } \\
\text { women } \\
\text { OR }(95 \% \mathrm{CI}) \dagger\end{array}$ & $\begin{array}{l}\text { Postmenopausal } \\
\text { women } \\
\text { OR }(95 \% \mathrm{CI}) \dagger\end{array}$ & $\begin{array}{l}\text { All } \\
\text { OR }(95 \% C I) \dagger\end{array}$ \\
\hline $\begin{array}{l}\text { Parity: } \\
0 \\
1 \\
2 \\
\geq 3 \\
\chi_{1}^{2}{ }_{1} \text { trend } \\
\text { Spontaneous abortions: }\end{array}$ & $\begin{array}{l}47: 43 \\
101: 93 \\
207: 219 \\
103: 106\end{array}$ & $\begin{array}{l}1 \\
1.3(0.6,2.8) \\
1.1(0.6,2.3) \\
1.0(0.5,2.3) \\
0.2\end{array}$ & $\begin{array}{l}1 \\
0.9(0.4,1.8) \\
0.9(0.5,1.7) \\
1.1(0.5,2.2) \\
0.2\end{array}$ & $\begin{array}{l}1 \\
1.1(0.7,1.9) \\
1.0(0.6,1.6) \\
1.1(0.6,1.8) \\
0.0\end{array}$ \\
\hline $\begin{array}{l}0 \\
\geq 1 \\
\text { Induced abortions: }\end{array}$ & $\begin{array}{l}355: 360 \\
102: 101\end{array}$ & $\begin{array}{l}1 \\
1.1(0.7,1.6)\end{array}$ & $\begin{array}{l}1 \\
1.0(0.6,1.7)\end{array}$ & $\begin{array}{l}1 \\
1.0(0.8,1.5)\end{array}$ \\
\hline $\begin{array}{l}0 \\
\geq 1 \\
\text { Age at first birth }(y):\end{array}$ & $\begin{array}{l}434: 440 \\
23: 21\end{array}$ & $1.4(0.7,2.9)$ & $\begin{array}{l}1 \\
0.3(0.1,1.9)\end{array}$ & $1.1(0.6,2.2)$ \\
\hline $\begin{array}{l}<25 \\
25-29 \\
\geq 30 \\
\chi^{2}{ }_{1} \text { trend } \\
\text { Age at last birth }(y):\end{array}$ & $\begin{array}{c}211: 211 \\
138: 158 \\
60: 47\end{array}$ & $\begin{array}{l}1 \\
0.8(0.5,1.2) \\
1.2(0.7,2.2) \\
0.0\end{array}$ & $\begin{array}{l}1 \\
0.7(0.4,1.1) \\
0.7(0.4,1.5) \\
1.6\end{array}$ & $\begin{array}{l}1 \\
0.8(0.6,1.1) \\
1.0(0.6,1.6) \\
0.4\end{array}$ \\
\hline $\begin{array}{l}<25 \\
25-29 \\
\geq 30 \\
\chi^{2}{ }_{1} \text { trend } \\
\text { Episodes of breast feeding: }\end{array}$ & $\begin{array}{c}204: 203 \\
144: 166 \\
63: 49\end{array}$ & $\begin{array}{l}1 \\
0.8(0.5,1.3) \\
1.3(0.7,2.4) \\
0.1\end{array}$ & $\begin{array}{l}1 \\
0.7(0.4,1.1) \\
0.7(0.3,1.4) \\
2.3\end{array}$ & $\begin{array}{l}1 \\
0.8(0.6,1.1) \\
1.0(0.6,1.6) \\
0.4\end{array}$ \\
\hline $\begin{array}{l}\text { Never } \\
1 \\
2 \\
\geq 3 \\
\chi^{2}{ }_{1} \text { trend } \\
\text { Months of breast feeding: }\end{array}$ & $\begin{array}{c}97: 102 \\
113: 113 \\
135: 139 \\
66: 64\end{array}$ & $\begin{array}{l}1 \\
1.2(0.7,2.1) \\
1.0(0.6,1.7) \\
1.2(0.6,2.4) \\
0.1\end{array}$ & $\begin{array}{l}1 \\
0.9(0.5,1.7) \\
0.9(0.5,1.5) \\
1.0(0.5,2.0) \\
0.0\end{array}$ & $\begin{array}{l}1 \\
1.1(0.7,1.6) \\
0.9(0.6,1.4) \\
1.1(0.7,1.8) \\
0.0\end{array}$ \\
\hline $\begin{array}{l}<6 \\
6-12 \\
\geq 12 \\
\chi_{1}^{2}, \text { trend }\end{array}$ & $\begin{array}{l}163: 148 \\
119: 107 \\
129: 163\end{array}$ & $\begin{array}{l}1 \\
1.1(0.7,1.8) \\
0.8(0.5,1.2) \\
1.1\end{array}$ & $\begin{array}{l}1 \\
1.2(0.7,2.0) \\
0.7(0.4,1.2) \\
1.5\end{array}$ & $\begin{array}{l}1 \\
1.1(0.8,1.6) \\
0.8(0.5,1.1) \\
2.7\end{array}$ \\
\hline
\end{tabular}

* Some strata do not add up to the total because of missing values.

† Odds ratios (OR) and $95 \%$ confidence intervals (CI) from unconditional multiple logistic regression equations including terms for age in quinquennia, body mass index in quintiles, and, when appropriate, menopausal status. $1=$ reference category.

creasing years after menopause was not linear (table 4).

Table 5 considers selected reproductive factors. No clear relationship emerged between any of them, including parity, abortion, age at first birth, and breast feeding and BMD.

Table 6 gives the parameter estimates from linear regression models where BMD was analysed as a continuous outcome variable. As in tertile based analysis, no significant relationship emerged between menstrual and reproductive variables and $B M D$. The only important explanatory variables were, again, those related to menopause. The coefficient for postmenopausal compared with premenopausal women was -0.092 (SE: 0.010). The coefficients for one year difference in age at menopause or years since menopause were equal $0.004(0.001)$.

\section{Discussion}

In this Italian population, the risk of being in the lowest BMD tertile decreased with increasing age at menopause and increased with years since menopause. No relationship emerged between BMD and other menstrual characteristics or reproductive factors. These results were confirmed when the analysis considered $\mathrm{BMD}$ as a continuous variable.

Before discussing these findings, potential strengths and limitations should be considered. Among the limitations, the reliance on one dual-photon absorptiometry examination at only one site (the lumbar spine) must be considered. ${ }^{10}$ The accuracy of BMD measurement from an antero-posterior projection of the spine can, for instance, be affected by osteophytes and soft tissue (especially aortic) calcifica-

Table 6 Regression coefficients* per unit of selected menstrual characteristics and reproductive factors as predictors of bone mineral density ( $\left(\mathrm{g} / \mathrm{cm}^{2}\right.$ ) at the lumbar spine in relation to menopausal status. Pordenone Province, north-east Italy, 1991-93

\begin{tabular}{|c|c|c|c|c|c|c|}
\hline \multirow[t]{2}{*}{ Variables } & \multicolumn{2}{|c|}{ Before menopause } & \multicolumn{2}{|c|}{ After menopause } & \multicolumn{2}{|l|}{ All } \\
\hline & $\beta$ & $S E(\beta)$ & $\beta$ & $S E(\beta)$ & $\beta$ & $S E(\beta)$ \\
\hline $\begin{array}{l}\text { Age at menarche ( } 1 \text { yr) } \\
\text { Length menstrual cycle ( } 1 \mathrm{~d} \text { ) } \\
\text { Irregular lifelong menstrual pattern (irregular vs regular) } \\
\text { Menstrual bleeding ( } 1 \mathrm{~d} \text { ) } \\
\text { Menopausal status (yes vs no) } \\
\text { Age at menopause }(1 \text { y) } \\
\text { Years since menopause ( } 1 \text { y) } \\
\text { Parity ( } 1 \text { birth) } \\
\text { Spontaneous abortions ( } 1) \\
\text { Induced abortions (1) } \\
\text { Age at first birth ( } 1 \text { y) } \\
\text { Age at last birth ( } 1 \text { y) } \\
\text { Episodes of breast feeding (1) } \\
\text { Breast feeding ( } 1 \text { mth) }\end{array}$ & $\begin{array}{r}0.0047 \\
-0.0083 \\
-0.0188 \\
-0.0009 \\
= \\
- \\
-0.0025 \\
0.0025 \\
-0.0137 \\
-0.0011 \\
-0.0015 \\
-0.0058 \\
-0.0005\end{array}$ & $\begin{array}{l}(0.0034) \\
(0.0082) \\
(0.0257) \\
(0.0037) \\
- \\
\overline{(} \\
(0.0029) \\
(0.0088) \\
(0.0148) \\
(0.0012) \\
(0.0012) \\
(0.0049) \\
(0.0008)\end{array}$ & $\begin{array}{r}-0.0061 \\
-0.0055 \\
0.0074 \\
-0.0037 \\
-\quad \\
0.0043 \\
-0.0042 \\
-0.0013 \\
-0.0030 \\
0.0125 \\
0.0010 \\
0.0011 \\
0.0041 \\
0.0011\end{array}$ & $\begin{array}{l}(0.0032) \\
(0.0088) \\
(0.0247) \\
(0.0034) \\
-(0.0012) \\
(0.0012) \\
(0.0032) \\
(0.0079) \\
(0.0317) \\
(0.0013) \\
(0.0013) \\
(0.0045) \\
(0.0008)\end{array}$ & $\begin{array}{r}-0.0009 \\
-0.0068 \\
-0.0042 \\
-0.0025 \\
-0.0916 \\
- \\
- \\
-0.0020 \\
-0.0003 \\
-0.0096 \\
-0.0002 \\
-0.0004 \\
0.0004 \\
0.0004\end{array}$ & $\begin{array}{l}(0.0023) \\
(0.0060) \\
(0.0178) \\
(0.0025) \\
(0.0102) \\
- \\
- \\
(0.0022) \\
(0.0059) \\
(0.0133) \\
(0.0009) \\
(0.0009) \\
(0.0006) \\
(0.0006)\end{array}$ \\
\hline
\end{tabular}

* Included in the regression were age at diagnosis, body mass index $\left(\mathrm{kg} \cdot \mathrm{m}^{1.5}\right)$ and, when appropriate, menopause status. 
tions, ${ }^{11}$ and precision errors related to ${ }^{153} \mathrm{GD}$ source age may be difficult to correct completely. ${ }^{12}$ However, these factors are unlikely to produce such strong and consistent associations as those observed in the present study with menopause-related variables. If they were not differential across BMD levels, they may well have reduced the association.

Other potential weaknesses concern the difficulty of establishing a useful osteoporosis threshold in a normally distributed healthy population around the age of menopause, and attributing to it a predictive value with regard to the subsequent fracture risk. While these problems cast serious doubts on the basis for a bone density screening, ${ }^{7}$ they do not eclipse the importance of elucidating the determinants of low bone density in different populations.

The strengths of the present investigation include the large number of women assessed, the relatively wide age range investigated, the availability of information on lifelong characteristics, and the low frequency of use of hormone replacement therapy, which may act as a confounding factor. Furthermore, the interview setting was such that neither the interviewer nor the women interviewed knew the outcome of the BMD measurements.

There is consistent evidence that oestrogens protect against osteoporosis. ${ }^{121314}$ In this, as in previous investigations, overweight postmenopausal women, who have higher available endogenous oestrogen levels, were a lower risk of osteoporosis. ${ }^{15}$

Menopause is associated with a massive decline in endogenous oestrogen levels, and there is considerable epidemiological evidence suggesting that early menopause increases the risk of osteoporosis. ${ }^{1315} \mathrm{We}$ have confirmed in this population that late menopause decreases the risk of osteoporosis. Whether such a protective effect persists in the years which follow menopause, and for how long, is, however, unclear. In this study, early age at menopause seemed a determinant of low BMD, both at the time and four or more years after the menopause. The risk of low BMD was still relatively low up to seven years after the menopause in women reporting menopause at age 50 or later. The risk of low BMD increased with years since the menopause to a similar extent in women who underwent the menopause before 50 years or at 50 years or later. This suggests that age at menopause and years since menopause may act independently on the risk of low BMD.

In biological terms, this may suggest that late menopause, and the consequently longer exposure to higher endogenous female hormone levels, tends to increase BMD levels. After menopause these levels fall and this decrease is independent of age at menopause. However, women with high BMD levels at the menopause may reach lower BMD levels later than women with low BMD levels at the menopause. Following this line of reasoning, the age at menopause and years since the menopause should be considered as possible indicators of oestrogen levels. However, since there is a perfect co-linearity between age, age at menopause, and time since menopause, the effect of these three variables is not estimable using a simple linear model.

The role of age at menarche and the lifelong menstrual pattern on the risk of osteoporosis is still undefined. ${ }^{16}$ An investigation conducted on young athletes suggested that irregular/long cycles are associated with low BMD. ${ }^{17}$ However, in that study only menstrual irregularity due to extreme physical activity was analysed. In this analysis, no association emerged between age at menarche, lifelong menstrual pattern, and risk of low BMD.

Likewise, data on the relationship between parity and osteoporosis are controversial. ${ }^{145}$ Oestrogen levels are raised during pregnancy, but pregnancy and lactation reduce calcium levels. ${ }^{5}$ Furthermore, some epidemiological studies have shown increased BMD in multiparous women, but others suggested losses during pregnancy. ${ }^{517}$ Also, the role of abortions on BMD is unclear. Our results do not support the existence of a relationship between pregnancy and osteoporosis, suggesting that reproductive factors have no major impact on the risk of osteoporosis in middle age and postmenopausal women.

The authors wish to thank "Via di Natale", Pordenone, for financial support, Mrs Rosalba Mazzega for interviewing study participants and Ivana Garimoldi and Judy Baggott for editorial assistance.

1 Cummings SR, Kelsey JL, Nevitt MC, O'Dowd KJ. Epidemiology of osteoporosis and osteoporotic fractures. $E p$ idemiol Rev 1985;7:178-208.

2 Slemenda C, Hui SL, Longcope C, Johnson C. Sex steroids and bone mass. A study of changes about the time of menopause. $\mathcal{F}$ Clin Invest 1987;80:1261-9.

3 Lindquist O, Bengtsson C, Hansson T, Roos B. Age at menopause and its relation to osteoporosis. Maturitas 1979;1(3):175-81

4 Kritz-Silverstein D, Barrett-Connor E, Hollenbach KA. Pregnancy and lactation as determinants of bone mineral density in postmenopausal women. Am 7 Epidemiol 1992; 136:1052-9.

5 Khastgir G, Studd J. Pregnancy-associated osteoporosis. $\mathrm{Br}$ f Obstet Gynaecol 1994;101:836-8.

6 Drinkwater BL, Nilson $\mathrm{K}$, Chesnut III $\mathrm{CH}$, Bremner WI, Shainholtz S, Southworth MB. Bone mineral content of amenorrheic and eumenorrheic athletes. $N$ Engl f Med 984;311:277-81

7 Law MR, Wald NJ. Meade TW. Strategies for prevention of osteoporosis and hip fracture. $B M \mathcal{F}$ 1991;303:453-9.

8 Bidoli E. The influence of body size, smoking, and diet on bone density in pre- and postmenopausal women. Epidemiology 1996;7:411-14.

9 Breslow NE, Day NE. Statistical methods in cancer research. Vol. I. The analysis of case-control studies. IARC Science Publications no 32. Lyon: International Agency for Research on Cancer, 1980.

10 Wasnich RD, Ross PD, Davis JW et al. A comparison of single and multi-site BMC measurements for assessment of spine fracture probability. $₹ \mathrm{Nucl} \mathrm{Med} 1989 ; 30: 1166-71$.

11 WHO Study Group on Assessment of Fracture Risk and its Application to Screening for Postmenopausal Osteoporosis. Assessment of fracture risk and its application to screening for postmenopausal osteoporosis: report of a World Health Organization Study Group. WHO Technical Report Series. Geneva: WHO, 1994:843.

12 Ross PD, Wasnich RD, Vogel JM. Precision error in dualphoton absorptiometry related to source age. Radiolog 1988;166:523-7.

13 Cauley JA, Gutal JP, Sandler RB, La Porte R, Kuller LH. Sashin $D$. The relationship of endogenous estrogen to bone density and bone area in normal postrogen to women. Am and bone area in normal pos

14 Sowers MFR Epidemiol 1986;124:752-61. premenopausal women. Epidemiol Rev 1993;15:374-98.

premenopausal women. Epidemiol Rev 1993;15:374-98.
15 Richelson LS, Wahner HW, Melton LJ 3rd, Riggs BL. Relative contributions of aging and estrogen deficiency to postmenopausal bone loss. $N$ Engl $\mathcal{F}$ Med 1984;311: to postmen.

16 Drinkwater BL, Bruemner B, Chesnut III C. Menstrual history as a determinant of current bone density in young athletes. $\mathcal{F} A M A$ 1990;263:545-8.

17 Christiansen C, Rodbro P, Heinild B. Unchanged total body calcium in normal human pregnancy. Acta Obstet Gynecol Scand 1976;55:141-3. 